\title{
CINE Y PICARESGA: I PICARI (1987), DE MARIO MONICELLI
}

\author{
Davide Mombelli \\ Universidad de Alicante
}

Mario Monicelli, gran cultivador de la picaresca, rinde un homenaje a este género en I picari (1987), largometraje que se presenta como un pastiche de diversas fuentes literarias clásicas. Guzmán de Alfarache (Giancarlo Giannini) y Lazarillo de Tormes (Enrico Montesano), que se encuentran casualmente atados a las cadenas de una galera, dan vida a una serie de divertidas e irreverentes escenas cómicas, una narración episódica que intenta traducir a un discurso cinematográfico las andanzas de estos dos impertérritos pícaros. Antes de adentrarnos en el comentario de la película, quizá sea oportuno apuntar algunas rápidas y sucintas reflexiones sobre los rasgos definitorios de la picaresca y su actualidad.

Para la comprensión de la literatura debemos prestar atención cuidadosa a todo lo que nos enseñe la erudición histórica, pero también debemos dejar que la obra literaria (situada debidamente dentro de su contexto histórico) nos hable a nuestra sensibilidad de hombres del siglo XX dentro del contexto más amplio de lo humano en general. La mayor parte de las obras geniales del pasado pugnan por desbordarse de lo estrictamente histórico y alcanzar este contexto de la universalidad. El Lazarillo la alcanza, por cierto; dentro de lo que yo llamo novela picaresca, en España creo que la alcanzan sólo Guzmán de Alfarache y Vida del Buscón (Parker, 1975: 27).

Con estas palabras Alexander A. Parker finaliza su introducción a un estudio fundamental sobre la picaresca española y su influencia europea: Los pícaros en la literatura: la novela picaresca en España y Europa (1599-1753). El pícaro es un tipo literario que cruza las fronteras de lo particular, el contexto de la España de los siglos XVI y XVII, para diluirse en lo universal. El harapiento protagonista de estas novelas va a ser el modelo de muchos relatos posteriores, tanto en España como en el resto del mundo. Ciñéndonos sólo al contexto nacional, en la literatura contemporánea podemos rastrear huellas de lo picaresco en obras como La lucha por la vida (1904) de Pío Baroja, las Nuevas andanzas y desventuras de Lazarillo de Tormes (1944) de Camilo José Cela, o en la novelística de Juan Antonio Zunzunegui. Como recuerda Ulrich Wicks, en estos textos el pícaro "ha sido transformado en una especie de huérfano arquetípico cuya vida representa una peregrinación baldía por un ambiente caótico en busca 
de un hogar o lugar propio en el mundo" (Eustis, 1986: 245). Eduardo Gómez de Baquero, 'Andrenio', se refería al mencionado libro barojiano en tanto que "trilogía picaresca", y veía en la resurrección llevada a cabo por el escritor vasco no un ensayo de mera imitación, sino un producto de la observación de la realidad; además, refiriéndose a La busca, primera pieza del tríptico, destacaba que su protagonista era un golfo, "el pícaro de los días actuales en una de las manifestaciones más genuinas" (Sobejano, 1964: 216).

En la actualidad, no sólo se ha intentado acercar la figura del pícaro a la del golfo, sino que se ha pretendido relacionarla con tipos sociales como el bohemio decimonónico (aunque Fernando Fernán-Gómez recuerda que éste no puede ser pícaro, ya que el bohemio "tiene que ser artista, soñar con la gloria", 1992: 173) o al hippie. El mismo Mario Monicelli, en una entrevista para La Repubblica (23/06/1987), afirmará que "i picari, in fondo, son attuali in tutte le epoche e in tutte le latitudini. Secondo me, ad esempio, i laceri ma vitalissimi protagonisti dell'altra Spagna del '500, che si inventavano la vita giorno per giorno, somigliano a tanti personaggi di Jack Kerouac, il vate della Beat Generation". Además, Ettore Scola, quien junto a Antonio Pietrangeli y a Ruggero Maccari escribió en 1960 un guión titulado La picaresca que no se llevó nunca al cine, definió su proyecto como "una especie de easy reader a la española" (Pineda, 1986). Por estos (y más) motivos, cineastas como Fernando Fernán-Gómez o Mario Monicelli, entre otros, pueden volver a presentar, en los años 70 y 80 , en la gran y en la pequeña pantalla, los trapicheos de esos vagabundos, sin que el discurso narrativo adquiera los tintes de un documental o una reconstrucción arqueológica. Lo picaresco es algo inmortal, una actitud frente al mundo y a sus injusticias, que aunaría figuras antropológicas de un pasado tanto remoto como más reciente. Sostiene Marcel Bataillon que "el pícaro literario, mientras no naufraga en la vulgaridad moralizadora, es siempre un filósofo cínico en mayor o menor medida, que se apresura a reírse de todo por miedo de verse obligado a llorar por ello mismo" (1973: 103).

La picaresca poseería, pues, unos determinados rasgos de modernidad que permiten a este género literario superar los límites cronológicos de su aparición: Alonso Zamora Vicente afirma que en 1554, año de publicación del anónimo Lazarillo de Tormes, "nace para el hombre occidental la novela moderna" (1962: 7). La innovación que supone esta literatura no reside sólo en el planteamiento narrativo estrictamente realista, sino que la misma configuración del protagonista en tanto que antihéroe es moderna: "el gran invento del Lazarillo no fue otro que el de hacer del hombre de carne y hueso, con sus flaquezas y su difícil persistir sobre la tierra, un personaje literario; antes de Lázaro, el personaje era un ente de ficción" (Zamora Vicente, 1962: 20).

El pícaro viene a ser un ejemplar antropológico-literario fundamentalmente arquetípico, cuyos rasgos definitorios se adaptan a las diferentes coordenadas sociales y culturales: "la concreción de la trayectoria vital del pícaro depende del significado que en cada época se adscribe al vocablo pícaro" (Meyer-Minnemann, 2008: 37). En otras, y más sencillas, palabras: cada época tiene sus pícaros. Está claro que el de los siglos de oro muestra un carácter y unas peculiaridades inevitablemente diferentes de las de quien se conoce como (a veces tergiversando su significado) "pícaro moderno". Además, dentro de la misma novela picaresca hay diversidad entre un Lazarillo, considerado como el "precursor", y un Guzmán, primer pícaro por antonomasia.

Ahora bien: ¿qué es una novela picaresca? Aunque Lázaro Carreter afirma que el de la novela picaresca, como ocurre con tantos conceptos operativos, "se resiste enérgicamente a 
ser definido" (1970: 27), Fernán-Gómez, valiéndose de los estudios del mismo Lázaro Carreter sobre el género, intenta proporcionar una definición: "real o fingida autobiografía de un desventurado sin escrúpulos, en la que el servicio del protagonista a varios amos facilita la crítica, y cuyo propósito es explicar un estado final de deshonor" (1992: 21).

En la picaresca hay crítica, pero no olvidemos que un objetivo de estos relatos era el de moralizar deleitando. Bataillon nos recuerda que "se debe al Lazarillo el que la novela picaresca sea heredera, en línea directa, de la literatura jocosa. No hay pícaro digno de narrarnos su vida si no tiene en su activo algunas buenas bribonadas o algunas fechorías dignas de la horca y si no es capaz de contarlas con gracia" (1973: 103). En efecto, nos reímos de las desgracias que persiguen a estos pobres desarrapados, una risa que, sin embargo, no se despoja casi nunca de un sentimiento de compasión. Es la sonrisa que brota de la miseria, la cual, como repetía Totò, es el guión de la verdadera comicidad. Monicelli sostiene que "la miseria ha costituito una fonte inesauribile di comicità. La risata diventava una possibilità di riscatto, una forma liberatoria, la voce dei perdenti che si leva contro le regole sociali" (Mondadori, 2005: 20), una convicción que acerca bastante la sensibilidad cómica y dramática del cineasta romano con la que fundamenta los relatos picarescos.

Lo cómico, como es bien sabido, tiene fecha de caducidad. Pero el humor que vertebra las aventuras de los pícaros se constituye de unos componentes que no acaban siendo anacrónicos, sino constantemente vivos: hay algo de splastick ante litteram en las escenas en las que un Guzmán acaba apaleado o manteado; y también algo de ingeniosidad, de agudeza exquisitamente barroca, que siguen asombrándonos. En suma, muchos (obviamente no todos) son los rasgos constitutivos de este género que han permitido volver a presentar en los escenarios y en las pantallas estos textos.

El Lazarillo de Tormes tiene varias transposiciones cinematográficas, todas españolas si se excluyen la versión de Monicelli y la del director georgiano Rezo Khotivari (Lazares tavgadasavali, 1973). La primera versión data de 1925 y fue dirigida por Florián Rey. Se trata de una trasposición a la época en que fue rodada la película. Como nos recuerda Luis Quesada (1986: 31), no queda ninguna copia del film, aunque sí algunas fotografías que nos muestran a la célebre actriz Carmen Viance y al pequeño actor Pitusín, pareja estelar de la película en la que también actuaba José Nieto, María Anaya y Manuel Montenegro.

La segunda adaptación es la llevada a cabo por César Ardavín en 1959. Marco Paoletti, joven actor italiano, interpretó a Lázaro, Carlos Casaravilla dio vida al papel del ciego y Juanjo Menéndez al del escudero. En esta película, el irónico proceso de ascenso a la honra se transforma en un itinerario de acercamiento a Dios. El film sortea así el anticlericalismo del original. Ardavín lima las asperezas y el desgarro típicos de la novela picaresca: "esa traición a la obra original está hecha en función de una razón de índole comercial que busca lograr un film amable, apto para grandes públicos, hurtando las lacras del pasado histórico español, más bien planteando el relato desde una posición literaria, culta, estilística, que asumiendo la carga ideológica, crítica, del autor anónimo" (Quesada, 1986: 32). El film obtuvo el Gran Premio Oso de Oro en el Festival de Berlín de 1960.

Fernando Fernán-Gómez, con Pedro y Emmanuela Beltrán, escribió los trece capítulos que componen la serie televisiva El Pícaro, estrenada por RTVE en 1973. Basándose en textos de Miguel de Cervantes, Francisco de Quevedo, Vicente Espinel, Mateo Alemán, Alonso Jerónimo de Salas Barbadillo, Alain René Lesage y en el Estebanillo González, Fernán-Gomez interpreta a un personaje, Lucas Trapaza, que, junto a su compañero de desventuras Alonso 
de Baeza, es el protagonista de un periplo existencial hasta su muerte, ya mayor, entre las paredes de un monasterio. Pero ésta no es la única ocasión en la que el autor de Las bicicletas son para el verano se enfrenta a la temática picaresca. En 1992 redacta el guión teatral de El Pícaro. Aventuras y desventuras de Lucas Maraña, y dos años después escribe una adaptación teatral del Lazarillo de Tormes, que llevará a la gran pantalla en 2001 con el título de Lázaro de Tormes (Rafael Álvarez, "El Brujo", es el protagonista, quien ya interpretó el mismo papel en la adaptación teatral de 1992); durante el rodaje, Fernán-Gómez enfermó y fue sustituido por José Luis García Sánchez.

Es en 1987 cuando Mario Monicelli, junto a Leo Benvenuti, Pietro de Bernardi e Suso Cecchi d'Amico, deciden ofrecer su versión de la picaresca, un género del cual el director romano presumía ser un buen conocedor ("ho sempre avuto una grande passione per Cervantes e i romanzi picareschi", Mondadori, 2005: 19). Con I picari no es la primera vez que el director romano se enfrenta a la traducción cinematográfica de textos clásicos. Inspirándose en la literatura burlesca y satírica medieval y renacentista (Luigi Pulci, Teofilo Folengo, Franco Sacchetti, Jacopone da Todi, entre otros), en 1966 estrena L'armata Brancaleone, en la que se narran las "hazañas" de un estrafalario caballero, Brancaleone da Norcia, interpretado por un extraordinario Vittorio Gassman, cuyo vagabundear sin meta se ha descrito mucha veces en tanto que "picaresco"; allí se presenta un Medievo sucio, mísero, animado por unos pobres harapientos, y vaciado de su dimensión caballeresca y cortés. Cuatro años después rueda una continuación: Brancaleone alle crociate (1970). Bertoldo, Bertoldino e Cacasenno (1984) es la trasposición de los textos de Giulio Cesare Croce (Le sottilissime astutie di Bertoldo, Le piacevoli et ridicolose simplicità di Bertoldino) y de Adriano Banchieri (Novella di Cacasenno, figliuolo del semplice Bertoldino), autores del Cinquecento que recogen y reelaboran antiguas novelle populares.

Tampoco es el primer cineasta italiano que decide trasponer al cine temas picarescos. Como ya hemos mencionado, en 1960 Ettore Scola, Ruggero Maccari y Antonio Petrangeli escriben un guión titulado La picaresca. Inspirado en la literatura del siglo XVI español, este texto narra la historia de Hernando y Tomé, "picaros" representantes de un pueblo obligado a (sobre)vivir en la miseria más sórdida. El relato de sus aventuras los sigue durante un continuo peregrinar, los observa ingeniarse para no perecer de hambre aprovechando todos los recursos de la inteligencia y de la malicia, analiza las diversidades de sus caracteres, hasta un final en el que vemos sucumbir al amigo menos fuerte, pero más disponible y sensible. Una escena "nella quale sono anticipati emblematicamente gli epigoni di tanti finali rivelatori dell'opera di Scola, di cui II sorpasso e Maccheroni sono gli esempi più eclatanti" (De Santi, 1987: 56).

El mismo Scola afirma que las novelas picarescas son unas fuentes inagotables de motivos cómicos para buena parte de la commedia all'italiana (Manzoli, 2004). En su reseña a I picari, Tullio Kezich escribió: "I'aggettivo 'picaresco', parlando della commedia all' italiana, I'abbiamo usato un'infinità di volte. Picaresco era il vagabondare dei bidonisti di Fellini, il rubacchiare dei 'soliti ignoti', il sorpasso tracotante di Gassman. Sicché il veterano Mario Monicelli paga una specie di debito dedicando un film a I picari, quelli garantiti d' epoca, e mettendo in scena la strana coppia formata dai famigerati Lazzarillo de Tormes e Guzman de Alfarache" (1987).

La afinidad que supuestamente acercaría la picaresca a la comedia italiana, aquella comicidad compartida y de raigambre latina, puede que resida, como sostiene Vittorio Gassman, 
en la posible cercanía entre el tipo literario del pícaro y el de las maschere de la commedia dell'arte: "[los pícaros] sono personaggi che possiamo far risalire alle maschere, ad una tipologia che noi facciamo benissimo, quella dei Grandi Stronzi, cialtroni, pezzenti e simpatici" (Fusco, 1987). La única (y sustancial) diferencia es que en muchos, pero no todos, de los relatos que narran la parábola existencial de los pícaros clásicos asistimos a una evolución psicológica y moral que no afecta a las tipificadas máscaras.

Hay otra característica que relaciona de una manera directa la poética de Monicelli con la de los textos picarescos. Ya hemos aludido a la "comicidad de la miseria". El director romano presta mucha atención a los vencidos, una actitud crítica y de denuncia que proviene de la influencia del neorrealismo italiano. Él mismo sostiene que "nella dimensione picaresca convivono allegria e crudeltà: due mondi contrapposti e speculari di guardare il mondo. La fame e la paura estremizzano i comportamenti umani" (Mondadori, 2005: 120). Varias de sus películas comparten una preocupación y una predilección hacia los desfavorecidos. Sin caer jamás en una visión paternalista, él conserva siempre una mirada lúcida y sardónica, nunca gratuita.

Aproximación temática, una muy similar sensibilidad cómica: la cercanía entre la picaresca y la commedia all'italiana está, creemos, bastante justificada. Podemos así introducir el comentario a la película de Monicelli, I picari, para averiguar las efectivas similitudes y las inevitables (y sustanciales) diferencias que diversifican los textos originales castellanos de la adaptación fílmica contemporánea.

La película, que se rodó en exteriores de Ávila, Salamanca, Toledo y otras localidades de Castilla y León (ciudades que se convierten en verdaderos personajes, más que en meros espacios físicos), comienza con la voz en off de Lazarillo (Enrico Montesano). El protagonista relata su niñez a un desconocido interlocutor, que descubrimos ser no el "vuestra merced" del original, sino otro pícaro, Guzmán de Alfarache (Giancarlo Giannini); los dos malhechores están encadenados el uno al otro en una galera. Monicelli respeta, por tanto, el planteamiento autobiográfico de las fuentes: la voz de Lázaro permite introducir una visión subjetiva que acompañará toda la película. Fernán-Gómez utilizará también un recurso muy similar en su adaptación cinematográfica: al principio de la película se presenta un primer plano de Lázaro, quien empieza a relatar su vida para defenderse delante de un tribunal mirando a cámara. Por su parte, Ardavín muestra en la primera escena una figura escorzada de un hombre que se revelará finalmente como el confesor al que el joven pícaro relatará sus fechorías. En todas las versiones fílmicas se organiza el discurso narrativo de tal forma que el espectador viene a ser el destinatario de una confesión existencial: a través de recursos muy parecidos, los tres directores ofrecen un relato biográfico en primera persona, característica, ésta, que, como mencionamos anteriormente en la definición del género, fundamenta el texto picaresco. Pero si en la película de Ardavín lo que vemos resulta ser una rememoración, y en la de Fernán-Gómez la narración está interrumpida por continuas analepsis, en el film de Monicelli los flash-backs se limitan a las primeras escenas, ya que a partir de la evasión de la galera seguimos las desventuras de los dos pícaros tal y como se van sucediendo, sin el filtro del recuerdo.

I picari no es en absoluto una traducción fidedigna al lenguaje audiovisual de la novela anónima del siglo XVI. Al igual que Fernán-Gómez en la serie El pícaro, Monicelli mezcla varios episodios extraídos de diferentes novelas picarescas, como si se concretara ficcionalmente lo que presenta el grabado de la portada de la primera edición de La Pícara Justina (1605). En este dibujo, "La nave de la vida picaresca" hospeda a Guzmán de Alfarache, Justina y la 
madre Celestina; en un barquito les sigue Lazarillo de Tormes. Curiosa coincidencia: Guzmán y Lázaro, en el film, se encuentran justo en una nave, más bien: una galera.

Volviendo a la cuestión de las fuentes, Monicelli maneja varios clásicos. Los principales son, por supuesto, el Guzmán de Alfarache de Mateo Alemán y El Lazarillo de Tormes. De éste se toman dos episodios: el del ciego, con el que empieza la película, y el del escudero de Toledo, al que volveremos después.

En la adaptación del "Tractado primero" del Lazarillo se nota, desde las primeras intervenciones, el toque personal del director romano con respecto al original. En el libro, Lázaro insinúa que su madre era una prostituta sólo indirectamente ("de manera que fue frecuentando las caballerizas", 2005: 15), dejando a la imaginación del oyente-lector la correcta interpretación de su afirmación. En la película, Lazarillo nos advierte abierta y descaradamente que su madre era una "puttana"; se añade así una nota de malicia declarada, y ya no ocultada detrás de un relato que, en el original, tenía que disimular el pasado poco noble del protagonista.

Lazarillo sigue contando su salida de casa y su ingreso en la vida pícara. Entra así en escena el ciego (Nino Manfredi). Si en el film se obvian episodios cómicos como el de la uva y el de la longanizas, se añaden, sin embargo, otros divertidos gags. Con la ingeniosa despedida del viejo acaba el recuerdo de Lazarillo, quien, y ésta es una diferencia sustancial con el libro, dirá: "dopo quello di padroni, io non ne ho più avuti"; de esta forma, se acentúa el sentimiento de libertad celebrado en la película.

La cámara enfoca entonces el interior de una galera. El espectador se entera así de la actual identidad de la voz narradora. A su lado está encadenado Guzmán de Alfarache, quien, después de padecer un par de latigazos, empieza la narración de su infancia. El episodio del padre de Guzmán, un famoso fullero que, descubierto por los aguaciles, va camino al cadalso sin perder nunca la sonrisa, es inédito y se aleja bastante del relato de Alemán, ya que en la obra el padre es tahúr, pero muere de enfermedad. Quizás podamos aquí hallar un guiño a La vida del Buscón de Quevedo, donde el padre de Pablos acaba ajusticiado y descuartizado. Además, el Guzmán de la película cuenta una divertida experiencia que no aparece en el original, en la que él, aún niño, está al servicio de una familia noble, obligado a padecer las puniciones que un severo maestro (Paolo Hendel) debería inferir al intocable "marchesino".

Terminado el recuerdo de Guzmán, la cámara vuelve a la galera y nos muestra un episodio libremente inspirado en el libro de Alemán. Los dos pícaros salvan fortuitamente la vida al capitán de la nave, y, como recompensa, pasan a su servicio. Las tareas que llevan a cabo los dos son, grosso modo, las expuestas en estas líneas del Guzmán: "matábale de noche la caspa, traíale las piernas, hacíale aire, quitábale las moscas con tanto puntualidad, que no había príncipe más bien servido, porque, se le sirven a él por amor, a el cómitre por temor del arco de pipa o anguila de cabo, que nunca se les cae de la mano" (1983: 884). Curiosa es la respuesta que Guzmán da al capitán, quien le interroga sobre su identidad: "Guzmán de Alfarache", le contesta, "de Mateo Alemán", una nota metaliteraria que no pasa desapercibida al espectador atento.

Los dos pícaros descubren la maquinación de un motín organizado por uno de los presos (Claudio Bisio, que debería hacer el papel de Soto en el obra), que finalmente delatan, como en la novela. Pero justo a partir de este momento tiene lugar un acontecimiento que, alejándose por completo del Guzmán literario, coincidirá con el verdadero inicio de las desventuras que ocuparán el resto de la película. En el original, Guzmán confiesa el intento de amotinamiento de Soto y compañeros al capitán, una buena acción que significará la definitiva redención del pícaro, quien empezará, desde entonces, a escribir, en calidad de hombre 
libre, sus memorias. De acuerdo con la dinámica de la ficción, inicia para el personaje literario el momento de la escritura, en la que él reflexionará y moralizará sobre su propia vida, un período de reposo que consiste en la composición efectiva del texto que acabamos de leer. Sin embargo, en la película los dos no tienen la misma suerte, ya que el motín llega finalmente a cumplirse, y los delatores se tirarán a la mar. Comienzan, por tanto, sus desgracias, pero ya no en una dimensión memorial y pseudo-ficticia como en la novela, sino en el tiempo real del presente. En el Lazarillo y en el Guzmán de Monicelli no se da ningún arrepentimiento: ellos siguen siendo pícaros. Arrojados a la cumbre del monte de las miserias, no deciden tocar el cielo y redimirse, sino que están obligados a bajar nueva y perpetuamente a los infernos de la precariedad y la indigencia, como nos desvelará el final. Los pícaros naufragan así en las costas mediterráneas españolas: desde este momento, sus vidas se cruzarán repetidamente, y sus destinos permanecerán imbricados.

En la escena en la que Lazarillo y Guzmán se refugian en un molino, Monicelli inserta una referencia explícita (y algo gratuita) a otro clásico de la literatura castellana. Oído un fuerte ruido, los dos, asustados, salen de sus cobijos para averiguar qué ha ocurrido. Grande es la sorpresa cuando ven a un extraño personaje en una armadura aplastado contra una de las palas del molino; este improbable individuo es el caballero de la Triste Figura. La cámara se distancia, y nos propone una imagen muy iconográfica: en un horizonte anaranjado por el atardecer resaltan las siluetas de Rocinante, Sancho Panza y su burro. Un guiño al amado Don Quijote.

Tras acudir a la casa de un carpintero para liberarse de las cadenas, Lazarillo afirmará: "siamo picari, vagabondi, la nostra vita non sarà un porto sicuro, ma è libera, bella". En estas palabras reside el significado más importante de la picaresca según Monicelli, un tema muy frecuentado por el director: la libertad de toda atadura social y moral. Y para obtener esta libertad, para conservarla, es inevitable viajar, ser nómada, no asentarse y conformarse nunca. Guzmán dirá: "un giorno qua, un giorno là: si va dove ci portano i piedi e la fortuna". Recuerda este deambular sin meta las zingarate de los pícaros (porque pícaros eran, aunque aburguesados) de Amici miei, unas ocasiones que les permitían ser libres, lejos del quehacer rutinario de la ciudad; un estado, el de zingaro, que tenía que ser momentáneo, porque la sociedad impone obligaciones: el trabajo, la familia,... y la vida otros escollos más serios e irrevocables: la enfermedad, la muerte. I picari es, por tanto, una sublimación de esta necesidad de huir, de ser libres, aunque el precio sea el hambre. "La vita", al fin y al cabo, "è un balocco", dice Guzmán.

El episodio siguiente es el del escudero (Tractado tercero del Lazarillo de Tormes), pero protagonizado, en la película, por Guzmán. Estamos en Toledo. El escudero es sustituido por el Marqués Alfonso Felipe de Alemón, conde de Guadarrama de Asturias, interpretado por Vittorio Gassman. Las diferencias son pocas pero sustanciales: en el Lazarillo el amo vuelve un día con un real, mientras que en la cinta es Guzmán quien, a través de un engaño, logra ganar una moneda, que lanza al suelo para que la pueda encontrar el Marqués. Éste la recoge, pero la entrega a un transeúnte que pasaba por ahí casualmente, no queriendo aceptar regalos que la fortuna y no su valor le proporcionaba. La figura del escudero de la novela y la del Marqués son bastante diferentes: Monicelli pasa por alto el sarcasmo con el que el autor (real) del Lazarillo pinta un retrato del noble decaído (quien, se nos cuenta, frecuentaba mujeres ilícitas), otorgando así al personaje una personalidad más sólida e inalterable, casi estatuaria, y por eso más patética. También el final se aleja bastante del original: el Marqués, después de 
haber regalado su caballo Barbarone a Guzmán, sale orgulloso de su casa, adelantando los aguaciles que irrumpieron en su palacio para prenderle por cuestiones de deudas. "Un nobile non scappa mai", sentenciará; y huir es lo que hace, por su parte, el escudero en la obra.

Lazarillo, después de haberse separado de Guzmán, vuelve a su antiguo "oficio", el del mendigo estafador. El director de una compañía de teatro ambulante descubre casualmente su innato talento interpretativo, y le ofrece un puesto de trabajo como San Sebastián en un drama litúrgico escrito para un convento. Durante la actuación, una monjita (Suor Trafitta delle Sette Spade) se enamora del joven y sensual santo. Le envía, por tanto, un mensaje, citándole para el día siguiente. Lazarillo acude a la cita a ciegas, convirtiéndose así automáticamente en un "galán de monjas". Entre la religiosa y el joven, separados por una inviolable rejilla, tiene lugar un sensual y a la vez grotesco diálogo tanto verbal como corporal, que Monicelli describe con una malicia, para no decir erotismo, muy típica de una parte de la commedia all'italiana (sobre todo la última, la de los años setenta, D'Amico, 2008: 211-221). Esta escena adapta un episodio del capítulo 9 del Libro III de La vida del Buscón de Quevedo, cuando Pablos entra en una compañía de comediantes y deviene él también galán de monjas.

Guzmán y Lazarillo vuelven a encontrarse en un puente de la ciudad, y deciden emprender nuevamente la vida pícara juntos. Escenifican, por tanto, el golpe de los "cannoli alla catalana", un engaño que podría recordar la famosa estafa de Guzmán a un mercader en Milán. Pero la verdadera fuente de este episodio ya no es una novela o un relato picarescos, sino que Monicelli se inspira a una escena del film II mattatore de Dino Risi, con Vittorio Gassman. En esta película Gerardo, el protagonista, estafa a un joyero con una estratagema prácticamente idéntica a la utilizada por los dos pícaros. Las fuentes literarias se mezclan con referencias cinematográficas contemporáneas, corroborando así la similitud y la afinidad que aunaría la comicidad y el ingenio típicamente picarescos al humor que identifica a las comedias italianas de los años 50 y 60.

Siguen las aventuras de la ya consolidada pareja de "truffatori". Llegados a un mesón, los dos deciden comprar los servicios de una prostituta, Rosario (interpretada por una bellísima Giuliana De Sio), a un rufián (Bernard Blier). Pero muy pronto los muchachos se percatan de la poca rentabilidad de su inversión. Rosario, de hecho, decide acostarse sólo con quien quiere, es decir, con jóvenes guapos y esbeltos. Este episodio inédito nos permite apuntar una reflexión sobre un recurso cómico que caracteriza la película, y que implica una inevitable distancia con la picaresca castellana. Rosario se expresa con un acento napolitano muy poco disimulado, así como Lazarillo-Montesano no rehúye ciertas inflexiones verbales que delatan su origen romano. Uno de los rasgos que fundamenta la commedia all'italiana es, sin duda, el dialecto. Piedras preciosas del fragmentado panorama lingüístico italiano, las diferentes variantes regionales, en las commedie all'italiana, son medios con los que los actores moldean a sus personajes, que devienen en la mayoría de los casos verdaderas macchiette, evolución de las maschere de la commedia dell'arte. En una declaración para el periódico La Repubblica durante las tomas de I picari en marzo de 1987, Monicelli afirma: "il linguaggio? A parte il fatto che i testi da cui ci siamo ispirati non sono in spagnolo antico, non sta a noi, italiani, fare una ricerca sul linguaggio letterario della Spagna. Senza parlare proprio in lingua perfetta, sono sicuro che ciascuno, durante le riprese, troverà un suo accento, una sua caratterizzazione non certo dialettale" (Fusco, 1987). Un desideratum, éste, no respetado finalmente por el director. Resultó imposible, por tanto, dar vida a tipos humanos tan estereotipados como los propuestos en el film sin utilizar el recurso cómico (porque el dialecto es cómico, genuino y 
fresco de por sí) del empleo, para algunos personajes, de las inflexiones del italiano regional. Afirma Sergio Frosati en La Nazione: "Teresa De Sio (sic) parla con improbabili accenti napoletani e Paolo Hendel con impreviste cadenze toscane. Ma allora siamo a casa nostra, si tratta solo di una commedia all'italiana tradizionale, lavata nei panni del Tago" (1987).

Debido a los caprichos de Rosario, los dos se separan nuevamente. Dejamos, por tanto, a Lazarillo, enamorado de la bella prostituta, y seguimos las andanzas de Guzmán, quien, para ganarse la vida, vuelve a desempolvar su viejo repertorio de tahúr con los dados. Entra así en la cofradía de Mozzafiato (Vittorio Caprioli). Este episodio está inspirado en la novela ejemplar de Cervantes Rinconete y Cortadillo. Mozzafiato-Monipodio, leída la "Memoria de las cuchilladas que se han de dar esta semana", encarga a Guzmán una cuchillada de catorce puntos que éste ha de inferir a un mercader. Pero el joven no logra llevar a cabo el encargo, y, descubierto por los aguaciles, asesina a uno de ellos, un desenlace muy similar al del Buscón.

Llegamos finalmente a la escena conclusiva: en la plaza de Arévalo la cámara enfoca un cadalso. Guzmán va camino del patíbulo en compañía de otro preso, un ladrón. Pero una fortuita coincidencia le salva de una muerte segura: el ayudante del verdugo es el mismo Lazarillo. Éste logra cambiar la identidad de los condenados, cortando así la mano derecha a Guzmán y ahorcando al ladrón. "Amico mio, la vita è un balocco", dirá Lazarillo, empuñando el hacha, irónica y resignadamente.

El final de I picari queda programáticamente abierto: Lazarillo y Guzmán intentan robar la leche a una oveja; descubiertos por el pastor, saltan la valla que encierra un simbólico rebaño, y huyen hacia un horizonte indeterminado, arropados por las notas de la canción de Lucio Dalla con la que se abrió la película: "Noi siamo picari, soprattutto siam liberi / [...] siamo diversi dai nostri simili / siamo maestri dei sogni impossibili". No hay ninguna redención posible, los dos no pueden pronunciar el "yo me arrepiento" que sanciona la vita nova del Lazarillo de Ardavín. "Y fueme peor, como vuestra merced verá en la segunda parte, pues nunca mejora su estado quien muda solamente de lugar y no de vida y costumbre" (Quevedo, 1990: 256): Monicelli no concede ningún espacio a la moraleja; sus personajes son irredimibles, lo que acercaría el planteamiento del italiano a una picaresca exquisitamente quevediana, texto excepcional (en todos los sentidos) en un género que tenía como objetivo hacer reír y divertir al lector, pero con la intención de moralizar y presentar lo que sería una vida que se desvía del buen camino de la virtud y de la fe cristiana.

Los picaros, según André Jolles (Mondadori, 2005: 117), aparecen atractivos por su levedad, amables con sus vicios. Esta sensación de libertad que desprende la figura del pícaro, una libertad que vale el precio del hambre y de la indigencia, asombraba al pícaro Monicelli: "i picari sono sradicati, fuori dalla società e senza legami solidi. Ma in questa precarietà c'è un gran fascino. Un senso avventuroso della vita, con i piaceri rubati, i pericoli da sventare e tutto quanto da inventare. Giorno dopo giorno, senza sapere cos'accadrà domani" (Mondadori, 2005: 125).

Pícaro, picaro: en italiano se nombra con la misma palabra al pobre vagabundo que recorría las polvorientas calles y plazas de la España de los siglos XVI y XVII. El mismo término sí, pero sin tilde: Monicelli, privilegiando el carácter cómico y burlesco de las vidas de estos jóvenes, deja de lado el acento trágico y patético del pícaro antiguo. Así se lamentaba "Colón" en las páginas del $A B C$ de Sevilla: "la realización de Monicelli es pobre. Tal vez se trate de agotamiento creativo [...] o de extrañamiento ante un medio cultural que le es ajeno", no teniendo I picari ninguna semejanza con "el humor negro y ácido de nuestros relatos de pícaros" (19-VI-1988). No es casual, por tanto, el hecho de que se decidiera titular en castellano 
la película Los alegres pícaros, una adjetivación que marcaría la distancia entre los originales y la adaptación.

La película no es, sin lugar a duda, de las mejores de Monicelli. Él mismo enumera sus defectos: "la scelta degli attori costituì un errore madornale. I picari dovevano farli due ragazzini di quattordici-quindici anni scappati di casa che andavano in giro privi di tutto: di morale, di soldi, di famiglia, pronto a qualsiasi avventura. Allegri e crudeli, ricorda. Al contrario Montesano e Giannini erano uomini fatti. Essendo costoso il film, per venderlo ai distributori della Warner che lo pagarono sulla carta, Di Clemente pretese degli attori di nome. E da quell'errore discendono tutti i difetti del film" (Mondadori, 2005: 124).

Pero el valor de I picari no reside tanto en la más o menos lograda traducción literal de unos clásicos de hace más de cuatro siglos. La inteligencia del director fue saber explotar una materia cómica aún viva, pero casi olvidada por el gran público. A pesar de que se le pueda criticar la supuesta incomprensión de algunos aspectos de la picaresca original, Monicelli supo revitalizar esos textos, ofreciendo a los espectadores una personal lectura interpretativa de la gran tradición picaresca castellana. Nuestro director firma así un verdadero homenaje a todos aquellos "picari di ieri e di oggi che popolano il suo cinema, questi maestri dei sogni impossibili che si muovono con l'assoluta inadeguatezza degli imbranati combinaguai nello spazio impregiudicato dell'avventura libera e allegra" (Caldiron, 2001: 143).

\section{BIBLIOGRAFÍA}

ALEMÁN, Mateo, Guzmán de Alfarache, ed. Francisco Rico, Barcelona, Planeta, 1983

BATAILLON, Marcel, Novedad y fecundidad del Lazarillo de Tormes, Salamanca, Anaya, 1973.

CALDIRON, Orio, "Maestri di sogni impossibili. L'immaginario picaresco", en Lo sguardo eclettico. Il cinema di Mario Monicelli, ed. L. De Franceschi, Venezia, Marsilio, 2001, pp. 132-145.

CARRETER, Fernando Lázaror, "Para una revisión del concepto de novela picaresca", en Actas del tercer congreso internacional de hispanistas, Carlos H. Magis (coord.), México, 1970, pp. 27-45.

CERVANTES, Miguel de, Novelas ejemplares (Vol. I), ed. Harry Sieber, Madrid, Cátedra, 1980. D'AMICO, Masolino, La commedia all'italiana. Il cinema comico in Italia dal 1945 al 1975, Milano, il Saggiatore, 2008.

DE SANTI, Pier Marco, I fim di Ettore Scola, Roma, Gremese Editore, 1987.

DELVINO, Romana, I film di Mario Monicelli, Roma, Gremese, 2008.

EUSTIS, Christopher, "La influencia del género picaresco en la novela española contemporánea", Thesaurus, Tomo XLI (1986), núm. 1, 2 y 3, pp. 225-255.

FERNÁN-GÓMEZ, Fernando, Historias de la picaresca, Barcelona, Planeta, 1992.

FROSATI, Sergio Frosati, "I picari di Mario Monicelli, La Nazione, 21/12/1987.

FUSCO, Maria Pia, "Miserabili, ma liberi", La Repubblica, 18/03/1987.

KEZICH, Tullio, "I soliti ignoti? Picari...", La Repubblica, 19/12/1987.

Lazarillo de Tormes, ed. Francisco Rico, Madrid, Cátedra, 2005.

MANZOLI, Giacomo, "L'armata Brancaleone, Enciclopedia del cinema, Roma, Treccani, 2004, consultado en

http://www.treccani.it/enciclopedia/l-armata-brancaleone (Enciclopedia del Cinema)/ (20/01/2013).

Quaderns, 8 (2013), pp. 7-17 
MEYER-MINNEMANN, Klaus, "El género de la novela picaresca", en La novela picaresca: concepto genérico y evolución del género (siglo XVI y XVII), K. Meyer-Minnemann (coord.), Madrid, Iberoamericana, 2008, pp. 13-40.

MONDADORI, Sebastiano, La commedia umana. Conversazioni con Mario Monicelli, Milano, II Saggiatore, 2005.

PARKER, Alexander A., Los pícaros en la literatura: la novela picaresca en España y Europa (1599-1753), Madrid, Gredos, 1975.

PINEDA, Vicente A., "Ettore Scola: 'El cine no puede cambiar la realidad, pero sí modificar algunas ideas'", $A B C, 03 / 11 / 1986$.

QUESADA, Luis, La novela española en el cine, Madrid, JC, 1986.

QUEVEDO, Francisco de, El Buscón, ed. Pablo Jauralde Pou, Madrid, Castalia, 1990.

SCOLA, Ettore, MACCARI, Ruggero y PIETRANGELI, Antonio, La picaresca: romanzo e sceneggiatura inediti, Mantua, Provincia di Mantova, 1984.

SOBEJANO, Gonzalo, "Sobre la novela picaresca contemporánea", Boletín Informativo de Derecho Político, n. 31 (1964), Salamanca, Universidad de Salamanca (Seminario de Derecho Político), pp. 213-225.

ZAMORA VICENTE, Alonso, Qué es la novela picaresca, Buenos Aires, Editorial Columba, 1962.

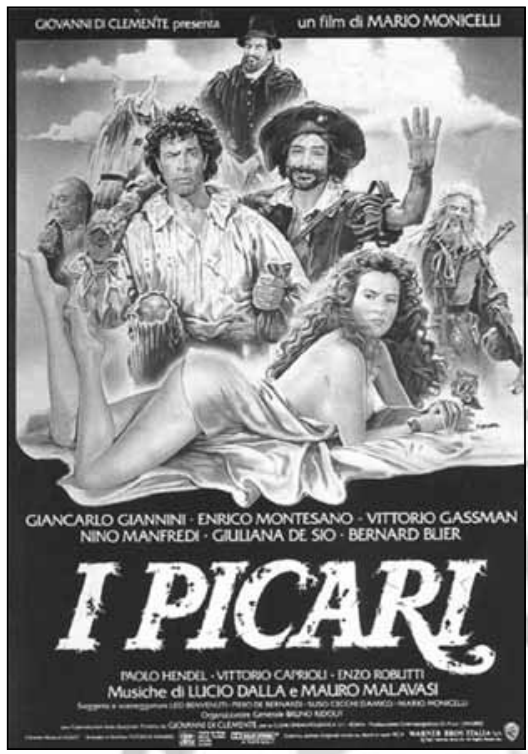

Fig. 1. Cartel de I picari.

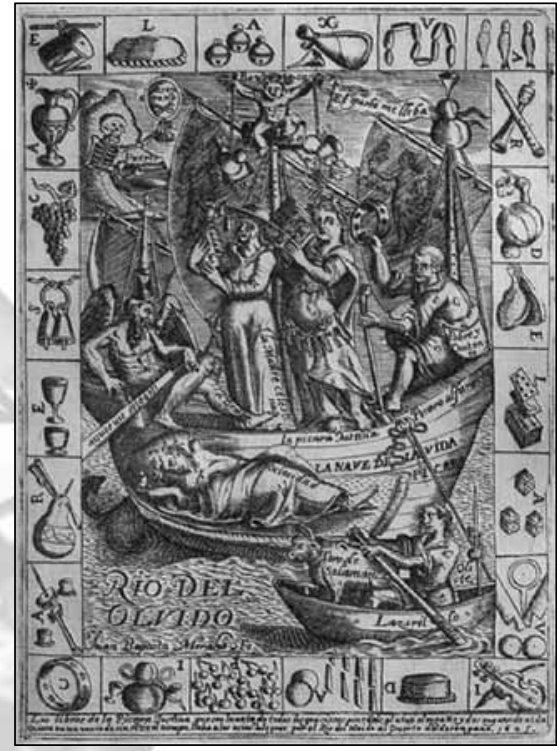

Fig. 2. La nave de la vida picaresca (Primera edición de La pícara Justina de 1605). 